\title{
The effects of shared situational awareness on functional and hospital outcomes of hospitalized older adults with heart failure
}

This article was published in the following Dove Press journal:

Journal of Multidisciplinary Healthcare

I July 2014

Number of times this article has been viewed

\author{
Joo H Lee' \\ Sun J Kim ${ }^{2,3}$ \\ Julia Lam ${ }^{4}$ \\ Sulgi Kim ${ }^{5}$ \\ Shunichi Nakagawa ${ }^{6}$ \\ JiW Yoo ${ }^{7,8}$ \\ 'Department of Media and \\ Communication, Hanyang University \\ College of Social Sciences, Seoul, \\ Korea; ${ }^{2}$ Department of Public \\ Health, ${ }^{3}$ Institute of Health Services \\ Research, Yonsei University College \\ of Medicine, Seoul, Korea; ${ }^{4}$ University \\ of Wisconsin School of Medicine \\ and Public Health, Madison, WI, USA; \\ ${ }^{5}$ Department of Epidemiology and \\ Biostatistics, Case Western Reserve \\ University, Cleveland, OH, USA; \\ ${ }^{6}$ Department of Medicine, Columbia \\ University College of Physicians and \\ Surgeons, New York, NY, USA; ${ }^{7}$ Center \\ for Senior Health and Longevity, \\ Aurora Health Care, ${ }^{8}$ Department \\ of Medicine, University of Wisconsin \\ School of Medicine and Public Health, \\ Milwaukee, WI, USA
}

Correspondence: Ji Won Yoo

Department of Medicine, University of Wisconsin School of Medicine and Public Health Center for Senior Health and Longevity, Aurora Health Care,

1020 N, I 2th St, \# 30I, Milwaukee,

WI 53233, USA

$\mathrm{Tel}+\mathrm{I} 4142197300$

Fax + | 4142197632

Emailyoo36@wisc.edu
Background: Functional decline of hospitalized older adults is common and triggers health care expenditures. Physical therapy can retard the functional decline that occurs during hospitalization. This study aims to examine whether shared situational awareness (SSA) intervention may enhance the benefits of physical therapy for hospitalized older persons with a common diagnosis, heart failure.

Method: An SSA intervention that involved daily multidisciplinary meetings was applied to the care of functionally declining older adults admitted to the medicine floor for heart failure. Covariates were matched between the intervention group $(n=473)$ and control group $(n=475)$. Both intervention and control groups received physical therapy for $\geq 0.5$ hours per day. The following three outcomes were compared between groups: 1) disability, 2) transition to skilled nursing facility (SNF, post-acute care setting), and 3) 30-day readmission rate.

Results: Disability was lower in the intervention group (28\%) than in the control group (37\%) (relative risk $[\mathrm{RR}]=0.74 ; 95 \%$ confidence interval $[\mathrm{CI}], 0.35-0.97 ; P=0.026$ ), and transition to SNF was lower in the intervention group (22\%) than in the control group $(30 \%)(\mathrm{RR}=0.77$; $95 \%$ CI, 0.39-0.98; $P=0.032$ ). The 30 -day readmission rate did not significantly differ between the two groups.

Conclusion: SSA intervention enhanced the benefits of physical therapy for functionally declining older adults. When applied to older adults with heart failure in the form of daily multidisciplinary meetings, SSA intervention improved functional outcomes and reduced transfer to SNFs after hospitalization.

Keywords: functionally impaired elderly, hospital communication system, hospital readmission, shared decision making, skilled nursing facility

\section{Introduction}

Hospital care utilization increases directly with age: the population aged 75 years or older spends, on average, 2.6 days per year in the hospital compared with 0.6 days for all other age groups. ${ }^{1}$ This can be a concern as the hospital setting is an immobilizing environment where patients may have multiple tethers - for example, intravenous lines, urinary catheters, and monitoring devices. A recent observational study reported that more than $70 \%$ of hospital stay was spent in bed, even among ambulatory seniors. ${ }^{2}$ Hospitalized older adults who are immobilized are particularly vulnerable to functional decline. ${ }^{3}$ There is evidence that such decline is prevalent in this population: one study showed hospital-associated functional decline in approximately one-third of a population aged 70 years and older. ${ }^{3}$ This decline can lead to adverse outcomes such as extended recovery periods and enrollment in nursing home facilities..$^{3-5}$ Another issue 
related to hospitalization is disability; hospitalization has been implicated as the strongest predictor of long-term disability in community-dwelling older persons. ${ }^{6}$

A potential solution to this problem is physical therapy. It has been shown to have a greater impact on patients at higher risk of functional decline at hospital admission than those at lower risk. ${ }^{7-10}$ However, very few studies have examined the benefits of physical therapy for hospitalized older adults, ${ }^{7-10}$ and to our knowledge, no study so far has examined means of enhancing the benefits of physical therapy in hospitalized older adults.

One possible means is shared mental models, which allow participants to predict information, organize task knowledge, and improve processes and performances. ${ }^{11}$ These models facilitate communication between hospital care providers and improve the outcomes in hospital care. ${ }^{12-14}$ Although initially introduced in the aviation industry, ${ }^{11}$ shared mental models have also been used in the health care industry. ${ }^{12-14}$ Similar care models, known as either interdisciplinary or multidisciplinary care models, for caring for older adults have been reported to improve inter-professional collaboration and to result in reducing adverse health outcomes and improving quality of care. ${ }^{15-17}$

Heart failure is one of the most common acute illnesses in hospitalized older adults. ${ }^{18}$ Hospital performance indicators such as 30-day readmission rate in heart failure are higher than those of other common acute illnesses (acute myocardial infarction and pneumonia). ${ }^{19,20}$ Therefore, we selected hospitalized older adults with heart failure who need urgent quality improvement.

Considering the evidence of their benefits, we hypothesized that shared mental models in the form of shared situational awareness (SSA) intervention can increase the benefits of physical therapy and improve functional and hospital outcomes of hospitalized older adults. Hence, we examined the effects of SSA intervention on 1) functional outcomes (as measured by developing disability as well as hospital discharge to a skilled nursing facility [SNF]) and 2) hospital outcome (as measured by 30-day hospital readmission rate) in this population.

\section{Methods}

\section{Study design overview}

The study site was a teaching metropolitan hospital in Cleveland, OH, USA (350 beds). The present study was a prospective and interventional study. The study period was from July 2007 to June 2008. Before enrolling study participants, priori analysis was performed to determine sample size as follows: disability with intervention $=25 \%$, disability with control $=30 \%$, alpha $=5 \%$, beta $=50 \%$, two-sided analysis, $10 \%$ extra data for possible follow-up loss, and estimated sample size in each group $=475$.

\section{Study participants}

Inclusion criteria were 1) community-dwelling age 65 years or older; 2) hospital admission to the general medicine floor under hospitalist service for principal diagnosis of heart failure (International Classification of Diseases, Ninth Revision, Clinical Modification: 402.01, 402.11, 402.91, 404.01, 404.03, 404.11, 404.13, 404.91, 404.93, and 428.0-428.9); 3) hospital length of stay (LOS) 3 days or longer (required to meet the 3-day inpatient rule to receive post-acute care at an SNF for 20 days without copayment under Medicare Part A); ${ }^{21}$ and 4) physical functional decline from 2 weeks prior to hospital admission, as indicated by changes in activities of daily living (ADL) from Stage 0 at pre-hospital admission to ADL Stage I at hospital admission. ADL stage has been validated and used as a well-established functional hierarchy tool. ${ }^{22,23} \mathrm{ADL}$ Stage 0 refers to the most independent, and Stage IV refers to the most dependent. A total of 1,275 participants were eligible for enrollment. Participants were excluded when they declined study participation $(n=104)$ or had either coexisting acute myocardial infarction or isolation precaution $(n=39)$. The number of study participants between the intervention and control groups was 1,132 . The number of allocated participants was 543 in the intervention and 589 in the control group. Due to incomplete data, 49 and 42 participants were withdrawn from the intervention and control groups, respectively. In the intervention group, 21 participants were lost due to in-hospital death $(\mathrm{n}=8)$ or referral to another hospital $(\mathrm{n}=13)$. In the control group, 72 participants were lost due to in-hospital death $(n=8)$, referral to another hospital $(n=8)$, or contamination from control to intervention group due to required urgent intervention $(n=56)$. The final number of analyzed participants was 473 in the intervention group and 475 in the control group. Figure 1 outlines the flow chart of sample enrollment, allocation, follow-up, and analysis based on the consolidated standards of reporting trials (CONSORT) statement. ${ }^{24}$ The study was approved by the institutional review board (equivalent to ethics committee) at Cleveland Clinic Health System. Individual subject consent was obtained from either patients or their caregivers when patients were mentally incapacitated.

\section{Intervention and control}

An intervention group was composed of both 1) physical therapy $\geq 0.5$ hour/day and 2) SSA care management. 


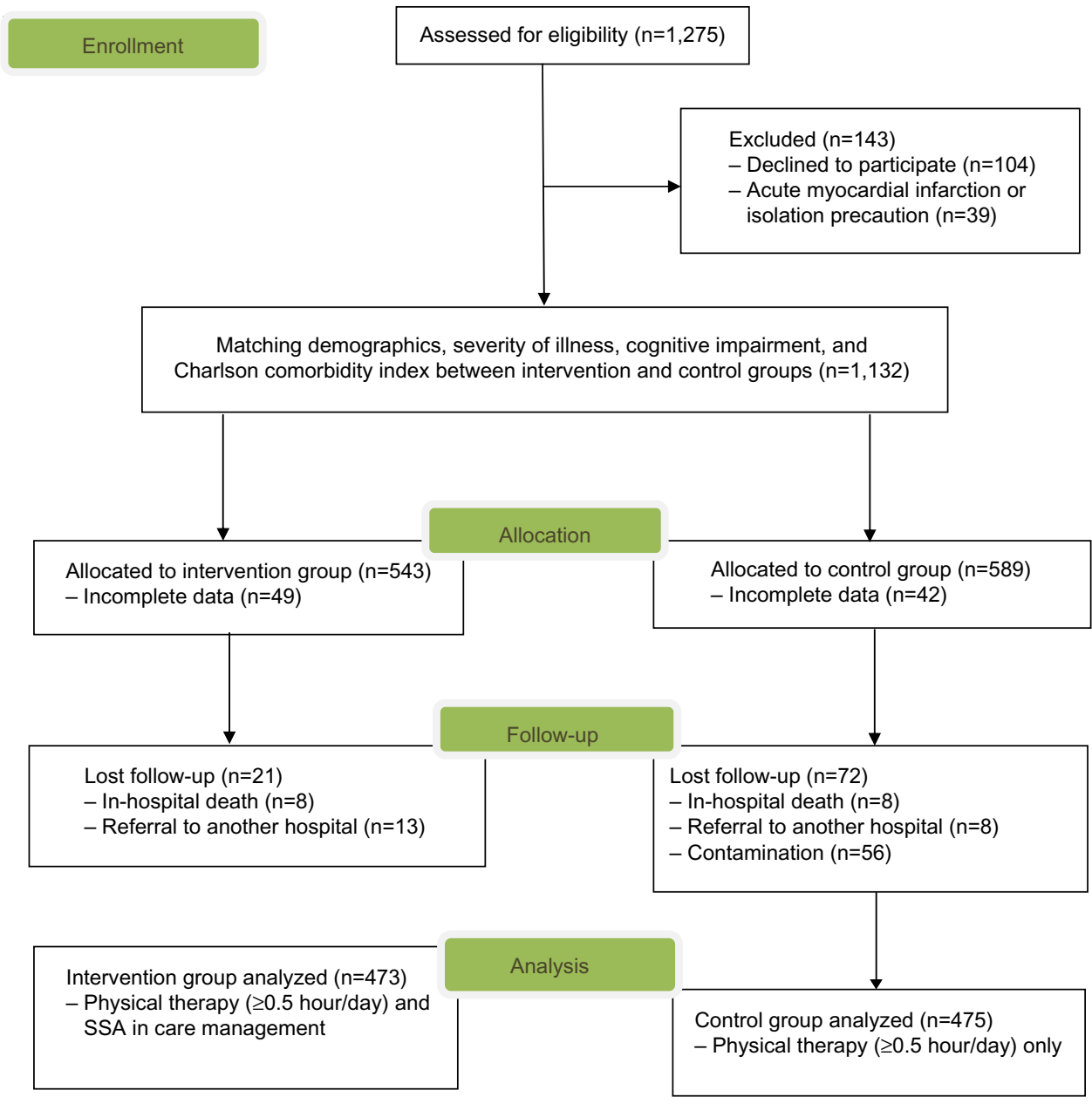

Figure I Flow chart of sample enrollment, allocation, follow-up, and analysis. Abbreviation: SSA, shared situational awareness.

A control was composed of physical therapy $\geq 0.5$ hour/day only. Study participants in both intervention and control groups received physical therapy for at least 3 days. We examined the hospital LOS across the sum of physical therapy hours. ${ }^{8,25,26}$ For example, we divided the sum of the physical therapy hours by the LOS. Physical therapy had specific modalities of ambulation (with or without device), muscle strengthening, gait transfer, and obstacle negotiation. The physical therapist was not aware of group allocation.

An SSA intervention was designed to enhance interpersonal communication among health care providers. Multidisciplinary meetings were held at the conference rooms of the general medicine floors during weekdays (Monday through Friday). Attendees of the SSA meetings were not aware of the group assignment and collaborated on assessment and management of diet compliance (sodium and fluid restrictions), medication compliance, and resource utilization compliance (clinic or home care visit), where they were updated on each health professional's opinions and shared approaches to solving problems in complicated situations. Attendees of the SSA meetings also discussed the progress of physical therapy and were able to modify specific therapy modality, duration, frequency, and intensity. All patients were discussed at these meetings, and the average time for each patient was approximately 2 minutes. All disciplinary health care professionals (physicians, nurses, case managers, social workers, physical therapists, speech/language therapists, pharmacists, and dietitians) were responsible for attending these meetings.

The study coordinator, who did not participate in patient care, randomly assigned patients to the intervention group using medical record number finishing either 1 or 5 when patients were admitted to hospital. The study coordinator derived control group participants using matching covariates (age, sex, ethnicity, All Patient Refined Diagnostic Related Group [APR-DRG] classification, cognitive impairment, and Charlson comorbidity index [CCI]) with the intervention group. When SSA meetings were necessary for the control 
group, we regarded contamination and excluded the participant from the study.

\section{Outcomes: I) disability, 2) transition to an SNF, and 3) 30-day hospital \\ readmission rate}

Hospital nursing staff examined physical function using ADL stage at three different times (pre-admission, hospital admission, and hospital discharge). Disability was defined as ADL Stage I-IV at the date of hospital discharge. Transition to SNF was defined as patient discharge to post-acute care settings (either SNF or inpatient rehabilitation facility). Referral to a facility where rehabilitation was not the primary purpose, such as a psychiatric facility, hospice, assisted-living facility, or adult foster home, was not considered as a transition to SNF. Thirty-day hospital readmission rate was defined as hospital readmission for heart failure within 30 days since hospital discharge.

\section{Covariates}

Covariates included age, sex, ethnicity, severity of illness, cognitive impairment, and CCI. The APR-DRG severity of illness classification system was used to estimate the severity of illness. The APR-DRG data were gathered based on the 3M Health Information Systems (Salt Lake City, UT, USA) tools. The APR-DRG has been used elsewhere for adjusting severity of illness in hospitalized patients with heart failure. ${ }^{27}$ Hospital nursing staff collected cognitive data using the Mini-CogTM screen (University of Washington, Seattle, WA, USA), which had the highest sensitivity (99\%) and correctly classified the greatest percentage ( $96 \%$ ) of subjects. ${ }^{28} \mathrm{CCI}$ has been validated for measuring comorbidity for hospitalized patients with heart failure. ${ }^{29,30}$ Due to incomplete data (less than $50 \%$ completion), the NYHA (New York Heart Association) heart failure classification was not used.

\section{Statistical analysis}

Bivariate comparisons of covariates between subjects of the intervention and control groups were examined using the chi-square test (categorical data) and Mann-Whitney $U$ test (continuous, not normally distributed data) as appropriate. All reported $P$-values were two-tailed, and $P<0.05$ was considered statistically significant. Multivariate log-binomial regressions were performed to compute relative risks (RRs) along with the corresponding 95\% confidence intervals (CIs) after adjusting for all covariates. RR $>1$ indicated that the outcome probability was higher in the intervention group than in the control group. Multicollinearity was tested using variation inflation factor. Goodness-of-fit of regressions were tested using the Hosmer-Lemeshow statistic. ${ }^{31}$ All statistics were performed using SAS statistical software version 9.3 (SAS Institute Inc., Cary, NC, USA).

\section{Results}

\section{Participant characteristics}

Table 1 presents characteristics between intervention $(n=473)$ and control group $(\mathrm{n}=475)$. The majority of participants were female and did not receive home health services. Participants were predominantly over age 80 years and white. The prevalence of cognitive impairment was approximately $20 \%$. Characteristics of intervention and control groups did not differ.

\section{Multivariate regressions of "disability", "transition to SNF", and "30-day readmission rate"}

Multivariate regression results of disability, transition to SNF, and 30-day readmission rate are shown in Table 2. Disability was classified by ADL stage. Disability at hospital discharge was lower in the intervention group (28\%) than in the control group $(37 \%$; RR $=0.74 ; 95 \%$ CI, 0.35-0.97; $P=0.026)$. Transition to SNF was lower in the intervention group $(22 \%)$ than in the control group $(30 \% ; \mathrm{RR}=0.77 ; 95 \%$ CI, $0.39-0.98 ; P=0.032)$. Thirty-day readmission rate was not statistically different between the groups (intervention group, $22 \%$; control group, $20 \% ; P=0.27$ ).

\section{Assessments of sensitivity and model fit}

Sensitivity analyses were used to explore alternative physical therapy threshold $\geq 0.66$ hour/day. Results for using

Table I Sample characteristics between intervention and control groups

\begin{tabular}{|c|c|c|c|}
\hline \multirow[t]{2}{*}{ Characteristic } & \multicolumn{2}{|l|}{ Percentage (N) } & \multirow[t]{2}{*}{$P$} \\
\hline & $\begin{array}{l}\text { Intervention } \\
\text { group, } n=473\end{array}$ & $\begin{array}{l}\text { Control } \\
\text { group, } n=475\end{array}$ & \\
\hline $\begin{array}{l}\text { Age, mean ( } \pm \text { standard } \\
\text { deviation) }\end{array}$ & $84.3(79.6-90.5)$ & $83.5(78.7-90.6)$ & 0.19 \\
\hline Female & $58(275)$ & $61(290)$ & 0.42 \\
\hline Non-whites & $39(183)$ & $36(170)$ & 0.31 \\
\hline \multicolumn{4}{|l|}{ Severity of illness (APR-DRG) } \\
\hline Mild & $23(108)$ & $20(94)$ & 0.16 \\
\hline Moderate & $29(138)$ & $34(162)$ & \\
\hline Major & $31(147)$ & $29(138)$ & \\
\hline Extreme & $17(80)$ & $17(8 \mathrm{I})$ & \\
\hline Cognitive impairment & $16(76)$ & $18(86)$ & 0.63 \\
\hline $\begin{array}{l}\text { Charlson comorbidity index, } \\
\text { mean ( } \pm \text { standard deviation) }\end{array}$ & $2.28(1.55-3.60)$ & $2.34(1.53-3.84)$ & 0.59 \\
\hline
\end{tabular}

Abbreviation: APR-DRG, All Patient Refined-Diagnosis Related Group. 
Table 2 Multivariate logistic regressions of "disability", "transition to a skilled nursing facility", and "30-day readmission rate"

\begin{tabular}{|c|c|c|c|c|}
\hline \multirow[t]{2}{*}{ Outcome } & \multicolumn{2}{|l|}{ Percentage (N) } & \multirow[t]{2}{*}{$\mathbf{R R}^{a}(95 \% \mathrm{Cl})$} & \multirow[t]{2}{*}{$P$} \\
\hline & Intervention group, $n=473$ & Control group, $n=475$ & & \\
\hline Disability & $28 \%(134)$ & $37 \%(174)$ & $0.74(0.35-0.97)$ & 0.026 \\
\hline ADL Stage I & $11 \%(53)$ & $17 \%(8 \mid)$ & & \\
\hline ADL Stage II & $8 \%(37)$ & $10 \%(46)$ & & \\
\hline ADL Stage III & $6 \%(28)$ & $6 \%(29)$ & & \\
\hline ADL Stage IV & $3 \%(16)$ & $4 \%(18)$ & & \\
\hline Transition to an SNF & $22 \%(105)$ & $30 \%(\mid 4 I)$ & $0.77(0.39-0.98)$ & 0.032 \\
\hline Thirty-day readmission rate & $22 \%(106)$ & $20 \%(94)$ & I.I3 (0.92-I.40) & 0.270 \\
\hline
\end{tabular}

Note: ${ }^{\mathrm{R} R}>\mathrm{I}$ indicates that the outcome probability is higher in the intervention group than in the control group.

Abbreviations: $\mathrm{ADL}$, activities of daily living; $\mathrm{Cl}$, confidence interval; RR, relative risk; SNF, skilled nursing facility.

physical therapy threshold $\geq 0.66$ hour/day were similar to results from the original category (physical therapy threshold $\geq 0.5$ hour/day), and were not included here. For example, the intervention group was associated with reduced disability and less transition to SNF, but there was no association between intervention and 30-day readmission rate. The maximum variation inflation factor was less than 10 ( 9.82 between age and cognitive impairment), and all covariates were included in logistic regressions. ${ }^{32}$ All logistic regressions fitted well as determined by Hosmer-Lemeshow test results ( $P=0.40$, disability; $P=0.58$, transition to $\mathrm{SNF}$; $P=0.81,30$-day readmission rate) ${ }^{31}$

\section{Discussion}

The present study examined whether SSA intervention in functionally declining older adults with heart failure is associated with functional and hospital outcomes. Our results showed that SSA intervention was associated with a lower occurrence of disability and fewer transitions to SNFs but was not associated with 30-day readmission rate.

Our observations on the disability rate during hospitalization were similar to previous reports on hospital-associated disability rate - approximately one-third of total subjects ( $28 \%$ of intervention group and $37 \%$ of control group). ${ }^{3,7,8}$ The consequence of interactions between the effects of hospitalization and aging leads to additional tiers in the cascade toward dysfunction and disability. ${ }^{33}$ By viewing functional decline as a multi-physiological systems dysregulation, instead of a single system failure, the "traction effects" crosses functional domains and leads to greater vulnerability to acute illness and early hospital readmission. ${ }^{34}$

The main benefits of physical therapy for hospitalized older adults when their physical function begins to decline are prevention and delay of traction effect of functional decline. These benefits of hospital-based physical therapy would be more effectively delivered through SSA intervention (ie, more organized care process, facilitated communication, and inter-professional collaboration as shown in previous multidisciplinary and interdisciplinary care for older adults). ${ }^{15-17}$

The present study makes a valuable contribution to the field considering the issue of excessive utilization of SNFs resulting from Medicare's controversial three-night rule (ie, Medicare covers SNF stay once older adults spend three nights or longer in hospital ${ }^{35,36}$ regardless of physical disability or illness severity). In fact, a review of approaches to reduce this excessive utilization is urgently required. ${ }^{37}$ Reducing transition to SNFs through SSA intervention may shed light on reductions in Medicare expenditures related to older persons' post-acute care.

Strategies of diet-control, medication adherence, and appropriate resource utilization are universally provided for older persons with heart failure at any acute care hospitals. ${ }^{37}$ The benefits of SSA intervention in this study can apply to innovations in health care processes, transforming fragmented to integrative care, during the management of the care of these hospitalized older adults with heart failure. SSA interventions through securing and maintaining the benefits of physical therapy after hospital care can improve functional outcomes, as suggested by health outcome assessment experts. ${ }^{38}$

Heart failure's 30-day readmission rate of the Medicare population has increased (known as the "revolving door" effect) over the recent decade due to a decreasing trend of hospital LOS. ${ }^{17}$ Heart failure is the most common cause of hospital care in the Medicare population. Medicare attempts to reduce the 30-day readmission rate of heart failure. ${ }^{39}$ No effect of SSA intervention on 30-day readmission rate can be interpreted that early hospital admission for heart failure may be more closely related to post-hospital care such as early clinic or home visit care. Post-hospital care, recent changes in medications, and care instructions may raise barriers to older adults with complex comorbidity, lack of transportation, and cognitive decline. Future research should compare the effects 
of SSA interventions (hospital and post-hospital care) on early readmission rate of older adults with heart failure.

Despite these important findings, our study has certain limitations. The first limitation is that in determining physical therapy intensity, we relied on the sum of physical therapy hours divided by hospital LOS. This method may not have entirely reflected the effects of the actual rehabilitation program. However, Jette et $\mathrm{al}^{40}$ observed that there was no clear pattern in rehabilitation therapy for specific diagnoses among patients receiving acute care in hospitals and that, eventually, the fundamental goal of rehabilitation therapy is functional recovery. Second, limited demographics in this study (older adults, predominant female, and metropolitan area in the Unites States) may not represent the outcomes of the whole heart-failure population. Third, we did not analyze the effects of SSA intervention on hospital revenues. Further analysis should determine whether SSA intervention would save more unnecessary costs of SNF utilizations or whether hospital revenue would shrink more if personnel attended SSA intervention meetings. Therefore, our analysis is preliminary until further, more representative, data are analyzed to confirm our findings.

\section{Conclusion}

SSA intervention enhanced the benefits of physical therapy for functionally declining older adults. When applied to older adults with heart failure in the form of daily multidisciplinary meetings, SSA improved functional outcomes and reduced transfer to SNFs after hospitalization.

\section{Acknowledgments}

This article was funded by an investigator-initiated grant from the American Geriatrics Society Junior Researcher Seed Grant. The authors were responsible for the design of the study, data collection and analysis, and preparation of the manuscript. The funding source had no such involvement. All authors confirm that all patient/personal identifiers have been removed or disguised so the patient/person(s) described are not identifiable and cannot be identified through the details of the story. The authors thank Ms Jamie Goehner who helped with the manuscript preparation and Ms Brenda Fay for literature search.

\section{Disclosure}

The authors disclose no financial conflicts of interest pertinent to this study.

\section{References}

1. Institute of Medicine. Retooling for an Aging America: Building the Health Care Workforce. Washington, DC: National Academy Press; 2008:45-49.
2. Pedersen MM, Bodilsen AC, Petersen J, et al. Twenty-four-hour mobility during acute hospitalization in older medical patients. J Gerontol A Biol Sci Med Sci. 2013;68(3):331-337.

3. Hoogerduijn JG, Schuurmans MJ, Duijnstee MS, de Rooij SE, Grypdonck MF. A systematic review of predictors and screening instruments to identify older hospitalized patients at risk for functional decline. J Clin Nurs. 2007;16(1):46-57.

4. Smith ER, Stevens AB. Predictors of discharges to a nursing home in a hospital-based cohort. J Am Med Dir Assoc. 2009;10(9):623-629.

5. Mudge AM, O'Rourke P, Denaro CP. Timing and risk factors for functional changes associated with medical hospitalization in older adults. J Gerontol A Biol Sci Med Sci. 2010;65(8):866-872.

6. Gill TM, Gahbauer EA, Murphy TE, Han L, Allore HG. Risk factors and precipitants of long-term disability in community mobility. Ann Intern Med. 2012;156(2):131-140.

7. Jones CT, Lowe AJ, MacGregor L, Brand CA. A randomized controlled trial of an exercise intervention to reduce functional decline and health service utilization in the hospitalized elderly. Australas $J$ Ageing. 2006;25(3):126-133

8. Yoo JW, Kim S, Choi JH, Ryu WS. Intensified rehabilitation therapy and transition to skilled nursing facilities in community-living seniors with acute medical illness. Geriatr Gerontol Int. 2013;13(3):547-554.

9. Nolan J, Thomas S. Targeted individual exercise programmes for older medical patients are feasible, and may change hospital and patient outcomes: a service improvement project. BMC Health Serv Res. $2008 ; 8: 250$.

10. Siebens H, Aronow H, Edwards D, Ghasemi Z. A randomized controlled trial of exercise to improve outcomes of acute hospitalization in older adults. J Am Geriatr Soc. 2000;48(12):1545-1552.

11. Mathieu JE, Heffner TS, Goodwin GF, Salas E, Cannon-Bowers JA. The influence of shared mental models on team process and performance. J Appl Psychol. 2000;85(2):273-283.

12. Gillespie BM, Gwinner K, Fairweather N, Chaboyer. Building shared situational awareness in surgery through distributed dialog. J Multidiscip Healthc. 2013;6:109-118.

13. de Vries EN, Ramrattan MA, Smorenburg SM, Gouma DJ, Boermeester MA. The incidence and nature of in-hospital adverse events: a systematic review. Qual Saf Health Care. 2008;17(3):216-223.

14. Wright M, Endsley M. Building shared situation awareness in healthcare settings. In: Nemeth C, editor. Improving Healthcare Team Communication: Building on Lessons from Aviation and Aerospace. Hampshire, UK: Ashgate; 2008.

15. Yoo JW, Seol H, Kim SJ, et al. Effects of hospitalist-directed interdisciplinary medicine floor service on hospital outcomes for seniors with acute medical illness. Geriatr Gerontol Int. 2014;14(1): 71-77.

16. Toles MP, Abbott KM, Hirschman KB, Naylor MD. Transitions in care among older adults receiving long-term services and supports. J Gerontol Nurs. 2012;38(11):40-47.

17. Naylor MD, Hirschman KB, Bowles KH, Bixby MB, Konick-McMahan J, Stephens C. Care coordination for cognitively impaired older adults and their caregivers. Home Health Care Serv Q. 2007;26(4):57-78.

18. Wier L, Pfuntner A, Steiner C. Hospital Utilization among Oldest Adults, 2008: Statistical Brief \#103. Healthcare Cost and Utilization Project. Rockville: Agency for Health Care Policy and Research; 2010.

19. Center for Outcomes Research and Evaluation. Hospital Quality Chartbook 2013: Risk-standardized readmission rates for heart failure. Washington, DC: Center for Medicare and Medicaid Services; 2013:19, $20,42,43$.

20. Bueno H, Ross JS, Wang Y, et al. Trends in length of stay and shortterm outcomes among Medicare patients hospitalized for heart failure, 1993-2006. JAMA. 2010;303(21):2141-2147.

21. Birmingham J. Understanding the Medicare "Extended Care Benefit" a.k.a. the 3-midnight rule. Porf Case Manag. 2008;13(1):7-16.

22. World Health Organization. International Classification of Functioning, Disability and Health: ICF. Geneva: World Health Organization; 2001. 
23. Stineman MG, Xie D, Pan Q, Kurichi JE, Saliba D, Streim J. Activity of daily living staging, chronic health conditions, and perceived lack of home accessibility features for elderly people living in the community. J Am Geriatr Soc. 2011;59(3):454-462.

24. Schulz KF, Altman DG, Moher D; for CONSORT Group. CONSORT 2010 statement: updated guidelines for reporting parallel group randomized trials. Ann Intern Med. 2010;152(11):726-732.

25. Jette DU, Warren R, Wirtalla C. Relationship between therapy intensity and outcomes of rehabilitation in skilled nursing facilities. Arch Phys Med Rehabil. 2005;86(3):373-379.

26. Lee WJ, Cheng YY, Liu CY, Peng LN, Liu LK, Chen LK. Dosedependent effect of rehabilitation in functional recovery of older patients in the post-acute care unit. Arch Gerontol Geriatr. 2012;54(3): e290-e293.

27. Carretta HJ, Chukmaitov A, Tang A, Shin J. Examination of hospital characteristics and patient quality outcomes using four inpatient quality indicators and 30-day all-cause mortality. Am J Med Qual. 2013;28(1): 46-55.

28. Borson S, Scanlan J, Brush M, Vitaliano P, Dokmak A. The mini-cog: a cognitive "vitals signs" measure for dementia screening in multilingual elderly. Int J Geriatr Psychiatry. 2000;15(11):1021-1027.

29. Charlson ME, Sax FL, MacKenzie CR, Fields SD, Braham RL, Douglas RG Jr. Assessing illness severity: does clinical judgment work? J Chronic Dis. 1986;39(6):439-452.

30. Lee DS, Donovan L, Austin PC, et al. Comparison of coding of heart failure and comorbidities in administrative and clinical data for use in outcomes research. Med Care. 2005;43(2):182-188.

31. Hosmer DW, Lemeshow S. Applied Logistic Regression. 2nd ed. Hoboken: John Wiley \& Sons, Inc.; 2005.
32. Hair JF, Anderson RE, Tatham RL, Black WC. Multivariate Data Analysis. 3rd ed. New York: Macmillan; 1995.

33. Fried LP, Xue QL, Cappola AR, et al. Nonlinear multisystem physiological dysregulation associated with frailty in older women: implications for etiology and treatment. Gerontol A Biol Sci Med Sci. 2009;64(10):1049-1057.

34. Kim SJ, Lee JH, Nakagawa S, et al. Predictors of hospitalization among newly admitted skilled nursing facility residents: rethinking the role of the functional decline. J Patient Res Rev. 2014. In press.

35. Pfuntner A, Wier LM, Steiner C. Statistical Brief \#146: Costs for Hospital Stays in the United States, 2010. Healthcare Cost and Utilization Project. Rockville: Agency for Health Care Policy and Research; 2010.

36. Medicare Payment Advisory Commission. Report to the Congress: Medicare Payment Policy. Chapter 7. Post-acute providers: shortcomings in Medicare's fee-for-service highlight the need for broad reforms. Washington, DC; 2013:151-156.

37. Islam T, O'Connell B, Lakhan P. Hospital readmission among older adults with congestive heart failure. Aust Health Rev. 2013;37(3) $362-368$.

38. Donabedian A. The quality of care: How can it be assessed? JAMA. 1988;260(12):1743-1748.

39. Medicare Payment Advisory Commission. Report to the Congress: Executive Summary of Medicare Payment Policy. Washington, DC: Medicare Payment Advisory Commission; 2013.

40. Jette DU, Brown R, Collette N, Friant W, Graves L. Physical therapists' management of patients in the acute care setting: an observational study. Phys Ther. 2009;89(11):1158-1181.
Video abstract

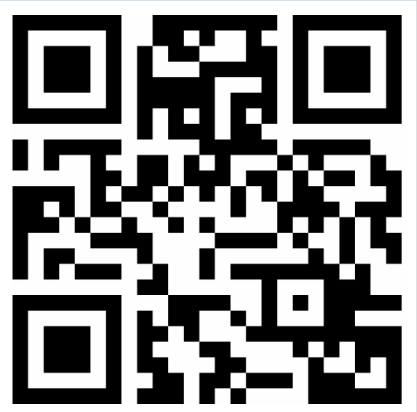

Point your SmartPhone at the code above. If you have a QR code reader the video abstract will appear. Or use: http://dvpr.es/ItXekFC
Journal of Multidisciplinary Healthcare

\section{Publish your work in this journal}

The Journal of Multidisciplinary Healthcare is an international, peerreviewed open-access journal that aims to represent and publish research in healthcare areas delivered by practitioners of different disciplines. This includes studies and reviews conducted by multidisciplinary teams as well as research which evaluates the results or conduct of such teams or

\section{Dovepress}

healthcare processes in general. The journal covers a wide range of areas and welcomes submission from practitioners at all levels, from all over the world. The manuscript management system is completely online and includes a very quick and fair peer-review system. Visit http://www.dovepress.com/testimonials.php to read real quotes from published authors. 